\title{
Development of TRIGA Fuel Fabrication by Powder Technique
}

\author{
H. Suwarno* \\ Center for Nuclear Fuel Technology, National Nuclear Energy Agency, \\ Puspiptek Area, Serpong 15314, Indonesia
}

\section{ARTICLE INFO}

Article history:

Received 22 October 2014

Received in revised form 29 December 2014 Accepted 31 December 2014

Keywords:

TRIGA

Pellet

Fuel Rod

Fabrication

\begin{abstract}
A B S T R A C T
The prospect of operation of the Indonesian TRIGA reactors may be jeopardizes in the future due to the lack of fuel and control rods. Both fuel and control rods may not longer be imported and should be developed domestically. The most specific technology to fabricate TRIGA fuel rod is the production of $\mathrm{UZrH}_{1.6}$ pellet. The steps include converting the massive $U$ metal into powder in by hydridingdehydriding technique and mixing the $\mathrm{U}$ and $\mathrm{Zr}$ powders. A research has been planned to conducted by the National Nuclear Energy Agency (BATAN) in Indonesia. Fixed amount of $\mathrm{U}-\mathrm{Zr}$ mixed powders at the ratio of $\mathrm{U} / \mathrm{Zr}=10 \mathrm{wt} \%$ was pressed into a pellet with a diameter of 1.41 in and a thickness of 1 or 1.5 in, sintered at a temperature of $1200^{\circ} \mathrm{C}$, followed by hydriding at $800^{\circ} \mathrm{C}$ to obtained $\mathrm{UZrH}_{1.6}$. The pellets, cladding, and other components were then fabricated into a fuel rod. A detailed discussion of the TRIGA fuel fabrication is presented in the paper.
\end{abstract}

\section{INTRODUCTION}

TRIGA (Training, Research, and Isotope production of General Atomic) is one of the oldest research reactors type in the world, developed by the General Atomic Inc. (GA). Several characteristics of TRIGA reactors and its fuel are described here [1,2]. First, TRIGA reactors are designed for training, research, and isotope production. Second, the reactors are considered inherently safe, allowing operation in rather densely populated areas (cities), and for reactor physics training of even inexperienced operators. Third, the unique feature of these fuel-moderator elements is the prompt negative temperature coefficient of reactivity, which gives the TRIGA reactor its builtin safety by automatically limiting the reactor power to a safe level in the event of a power excursion. Fourth, the costs per year are very low compared to those of other types of research reactors. Fifth, the heat capacity of $\mathrm{U}-\mathrm{ZrH}_{1,6}$ is large enough so that the size of the fuel rod geometry is relatively small and the high prices of thermal neutron flux due to the high concentration of hydrogen. Sixth, similar to other MTR type reactors, TRIGA was designed with an open pond systems with natural convection or forced cooling, depending on the capacity of the reactor. Finally, the reactor offers a very high pulse

\footnotetext{
Corresponding author.

E-mail address: hadis@batan.go.id
}

capability with reactivity insertion of $3.2 \% \delta \mathrm{k} / \mathrm{k}$ (\$ 4.60) and $6500 \mathrm{MW}$ peak power capable of producing neutron flux $\sim 10^{15} \mathrm{~N} / \mathrm{cm}^{2}$ each pulse.

The license of the fuels fabrication for TRIGA was transferred from the GA (USA) to CERCA (France), many years ago. Recently, it was announced that the CERCA will close the TRIGA fabrication line primarily to establish a significant capital investment to upgrade the facility based on a commitment to the novel licensing requirements of the French regulatory authority [3]. Consequently, all the TRIGA reactors in the world would be stopped operation due to unavailable fresh fuels to sustain the operation.

TRIGA-2000, Bandung, and TRIGA-Kartini, Jogyakarta, operated by the National Nuclear Energy Agency (BATAN), Indonesia, have been experiencing lack of fresh fuels and control rods. The reactors are relatively old (> 45 years) but have been proven to operate safely for research activities in the fields of nuclear technology, health, agricultural, and operators training[4]. Since constructing a new research reactor seems costly, therefore, continuing the operation of the reactor by self developing the fuels looks the best considering.

The center for nuclear fuel technology (PTBBN) in BATAN has been experiencing in producing the $\mathrm{U}_{3} \mathrm{Si}_{2}-\mathrm{Al}$ MTR plate-type fuels. Conducting the R\&D of the TRIGA fuel rod (including control rod) to assure continuous supply of TRIGA fuel into the future becomes reasonable. 
Technical information about TRIGA fuel technology is not available in journal. The study was undertaken making use of data available in the open sources as well as experience of the Author in making $\mathrm{UZrH}_{1.6}$ alloy, hence the idea of making TRIGA fuel can be materialized.

\section{EXPERIMENTAL METHODS}

\section{TRIGA fabrication by the GA}

According to the master document images of the TRIGA MARK II reactor type, the $\mathrm{U}-\mathrm{ZrH}_{1.6}$ pellet for TRIGA-2000 fuel has dimensions of 15 in long, 1.41 in in diameter, with a hole diameter of 0.225 in [5]. Figure 1 shows a schematic diagram of the TRIGA-2000 fuel element, Bandung.

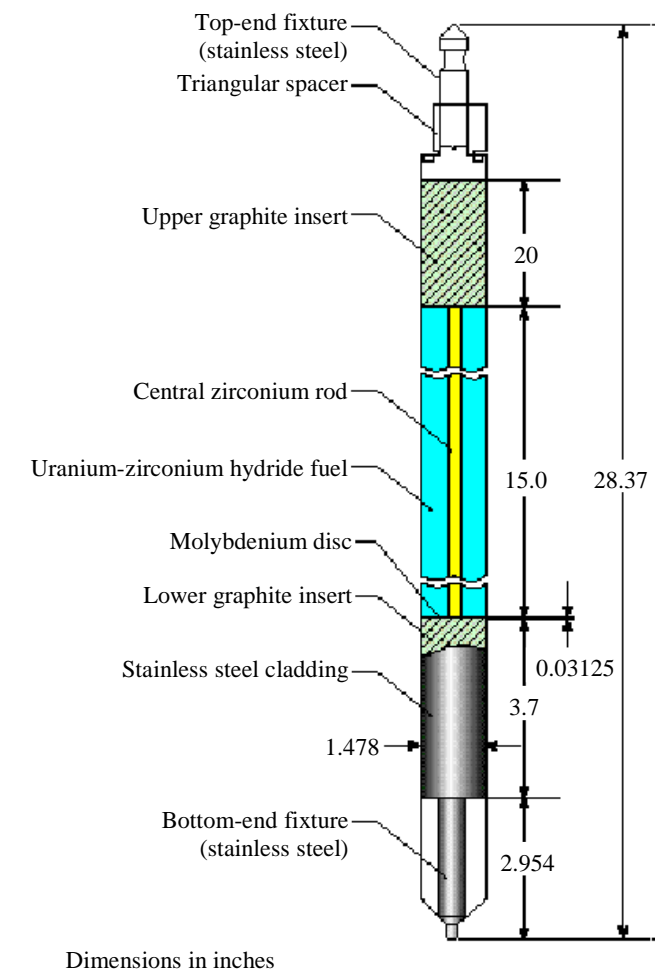

Fig. 1. Schematic figure of the GA TRIGA-2000 fuel rod [5].

From the information collected, the estimation for manufacturing process according to the GA TRIGA fuel is as follows [6-8]. Uranium metal in the form of chips and zirconium sponge (standard composition containing 8.5 to $12 \mathrm{wt} \%$ uranium enriched at $<20 \%$ ) were pressed in a pressing machine at a power of 30 tons / sqin forming massive metal bars with a diameter of 1 in and a length of 12 in. Every two rods of $\mathrm{UZr}$ are welded to form a long rod with the length of about 24 in. These massive UZr bars will function as an electrode in the melting process.
By using an arc melting furnace the $\mathrm{UZr}$ bars are melted into ingot with the diameter of about 4 in. The imperfect form of the melted ingots can be remelted again to obtain a homogeneous form. The UZr ingot is then shrinked into a solid bar with a final diameter of 3.8 in in a turning lathe machine. The UZr bar is then immersed in an organic liquid to clean the surface of bar from the contaminants before finally turning into a pellet. In the hydriding system, the pellet is hydrided until the $\mathrm{H} / \mathrm{Zr}$ ratio $=1.6$ was obtained. Hydriding conditions must be controlled such that avoiding the formation of $\mathrm{UH}_{3}$ compound. Pellets $\mathrm{U}-\mathrm{ZrH}_{1.6}$ obtained is then ready to be fabricated with SS cladding and other components into a TRIGA fuel rod.

From the patent [9] it was informed that the hydrogen content in the range of U-Zr alloys may vary from $\mathrm{U}-\mathrm{ZrHx}$ with an $\mathrm{x}$ value of $=1.1 \sim 1.7$. However, the content of $\mathrm{H}$ does not exceed 1.8 because it will lead the pellets to crack and rupture.

\section{Proposed technique}

To make pellets with a length of 5 15 in according to the GA patent [6] special tools are required and cannot be procurred by the PTBBN. Therefore, it is necessary to modify the process through by powder technique by hydriding-dehydriding of the uranium metal and changing the thickness of the pellets from 5 in into 1.0 or 1.5 in depending on the results of the experiment. In addition, this method differs from the manufacturing process according to that patented by the GA.

Figure 2 shows the TRIGA-2000 Bandung and TRIGA-Kartini fuel manufacturing process that is being proposed, with the difference method as developed by GA, namely through the powder technique.

A short sequence of the new manufacturing process is as follows. $\mathrm{U}$ massive metal is hydrided at a temperature of $300^{\circ} \mathrm{C}$ and converted into $\mathrm{UH}_{3}$ powder. At $550^{\circ} \mathrm{C}$ the $\mathrm{UH}_{3}$ powders will decompose into $\mathrm{U}$ powder and $\mathrm{H}_{2}$ gas. $\mathrm{U}$ metal powders are then mixed with $\mathrm{Zr}$ metal powders with a weight ratio of $U / Z r=10 \mathrm{wt} \%$, pressed into a pellet, followed by sintering at $1200^{\circ} \mathrm{C}$. After sintering, the pellet is hydrided at of $800^{\circ} \mathrm{C}$ until the $\mathrm{UZrH}_{1.6}$ pellet formed with final dimensions of 1.41 in diameter and 1 or 1.5 in thickness. As many as 10 or 15 pellets are assembled with stainless steel cladding and other components (graphites and $\mathrm{Zr}$ rod) into a TRIGA fuel rod. 


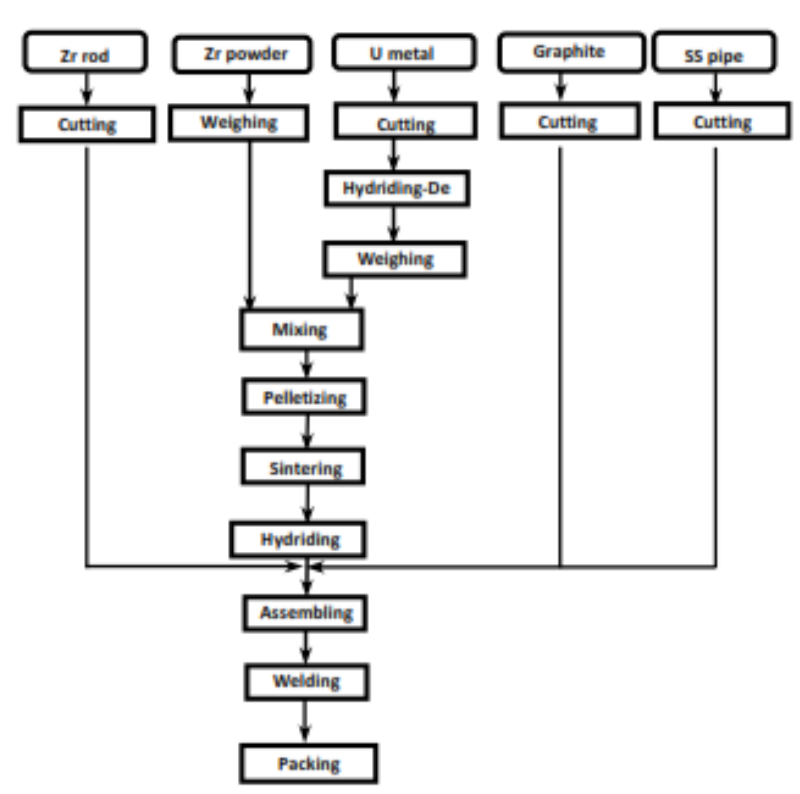

Fig. 2. Proposed flow diagram of the TRIGA-2000 fuel fabrication.

Figure 3 shows a $\mathrm{U}-\mathrm{ZrH}_{1.6}$ pellets with the length of 1 or 1.5 in is being prepared, where to get the 15.0 in long will require 10 or 15 pellets.

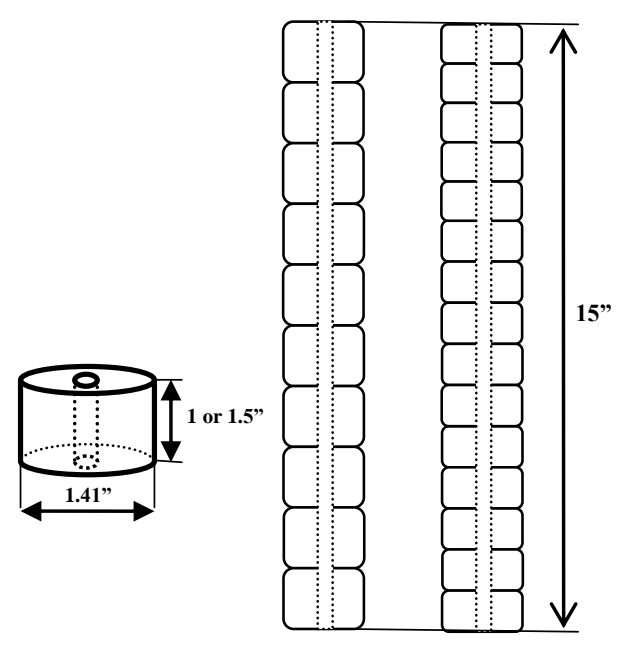

Fig. 3. Schematic figure of a pellet or 10 or $15 \mathrm{UZrH}_{1.6}$ pellets to be prepared.

\section{RESULTS AND DISCUSSION}

\section{U powder preparation}

In order to prepare the $U$ metal powder from the massive metal a hydriding-dehydriding process is conducted. The Author has done this experiment many times and one of the results is shown in Fig. 4 [10,11]. Before hydriding, the $\mathrm{U}$ metal is cleaned from impurities, particularly oxides of metal attached to the metal surface by pickling in nitric acid solution at a temperature of $70{ }^{\circ} \mathrm{C}$. Fig. 4 a is the $\mathrm{U}$ metal before hydriding and Fig. $4 \mathrm{~b}$ is the result after hydriding at a temperature of $300^{\circ} \mathrm{C}$. The $\mathrm{U}$ chips having dimension of $5 \sim 15 \mathrm{~mm}$ and $\pm 5 \mathrm{~mm}$ thick turned into powders, which indicates the formation of $\mathrm{UH}_{3}$. When the temperature is raised to a temperature of $550^{\circ} \mathrm{C}$, the $\mathrm{UH}_{3}$ will decompose into metallic $\mathrm{U}$ and $\mathrm{H}_{2}$ gas. Hydriding-dehydriding reaction can be written as follows:

$$
2 \mathrm{U}+3 \mathrm{H}_{2} \stackrel{300^{\circ} \mathrm{C}}{\longrightarrow} 2 \mathrm{UH}_{3} \stackrel{550^{\circ} \mathrm{C}}{\longrightarrow} 2 \mathrm{U}+3 \mathrm{H}_{2}(1)
$$

From the U-H phase diagram, the decomposition reaction of $\mathrm{UH}_{3}$ occurs at a temperature of $>429^{\circ} \mathrm{C}$, so that the selected temperature of $550^{\circ} \mathrm{C}$ in vacuum pressure is adequate, as shown in Fig. 5 [12]. By this method the powders size obtained were $45 \sim 100 \mu \mathrm{m}$.

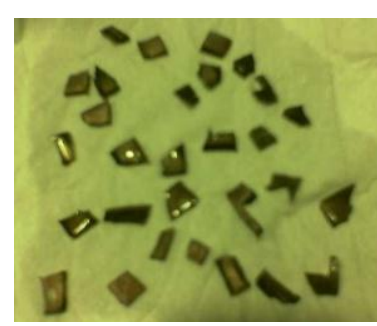

(a)

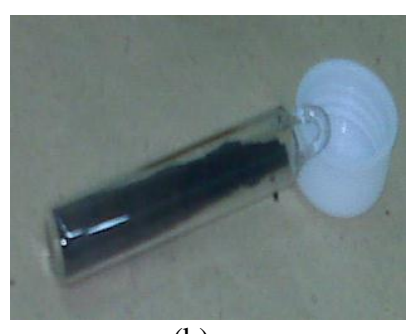

(b)
Fig. 4. Metal U chips before hydriding (a) and U powder after hydriding at a temperature of $300^{\circ} \mathrm{C}$ and dehydriding at $550^{\circ} \mathrm{C}(\mathrm{b})$.

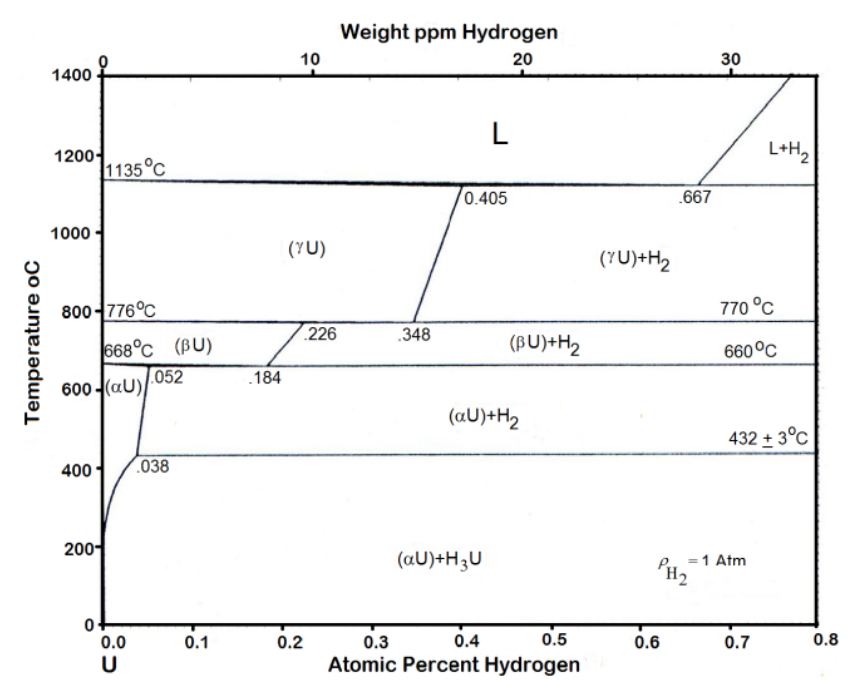

Fig. 5. Phase diagram of uranium-hydrogen[12].

\section{Mixing of $U$ and $Z r$ powders}

The mixing of $\mathrm{U}$ and $\mathrm{Zr}$ powders is conducted in a blender having rotation angle of $45^{\circ}$. The blender rpm can be adjusted to $120 \mathrm{rpm}$, the volume of mixing holder is $250 \mathrm{~cm} 3$, the $\mathrm{U} / \mathrm{Zr}$ 
ratio $=10 \mathrm{wt} \%$, the ball to powders ratio $=8$, and the blending-time is set to $45 \mathrm{mins}$. To determine the optimum blending time the Fourier transform method is used [13]. Figure 6 shows the blender to be used in the experiment.

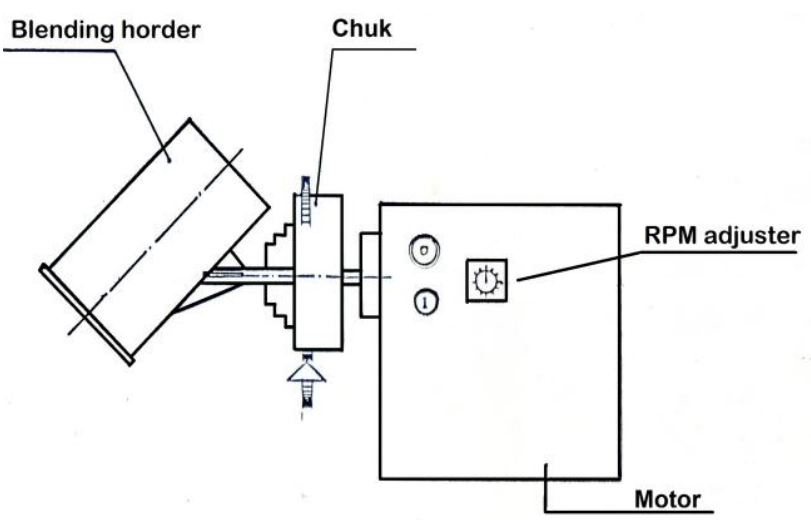

Fig. 6. Tumbler Mixer for blending the $\mathrm{U}$ and $\mathrm{Zr}$ powders.

\section{U-Zr pellet preparation}

Figure 7 shows the press machine capacity to be used for $\mathrm{U}-\mathrm{Zr}$ pellet preparation. The machine has maximum capacity of $6000 \mathrm{KN}$ and capable for producing U-Zr pellet [14]. Special dies should be provided for preparing U-ZR pellets according to the TRIGA specification. According to calculation, to prepare a pellet having dimension of 1.41 in in diameter, thickness of 1.0 or $1.5 \mathrm{in}$, and porosity of $\pm 5 \%$ requires a pressure of about 130 bar [15].

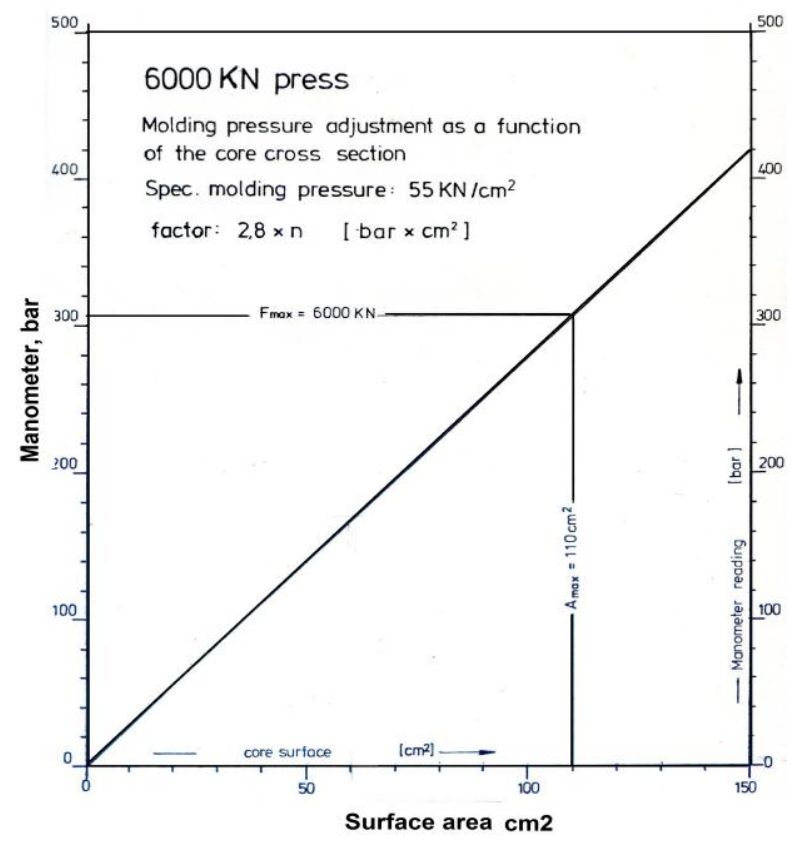

Fig. 7. Press machine specification for $\mathrm{U}-\mathrm{Zr}$ pellet preparation [14].

\section{Calculating the $\mathrm{U}-\mathrm{ZrH}_{1.6}$ composition and hydriding}

To introduce hydrogen into the UZr alloy to form $\mathrm{UZrH}_{1.6}$ a hydriding-dehydriding system was developed by the Author, based on the Sievert system, and presented in Fig. 8 [16,17]. The operation of the system has been presented elsewhere. After an UZr pellet put in the system, it is evacuated $>1.10^{-5} \mathrm{mbar}$, and heated up to a temperature of $800^{\circ} \mathrm{C}$ stepwisely. At $800^{\circ} \mathrm{C}$ the hydrogen gas is flowed into the system accurately until an atomic ratio of $\mathrm{H} / \mathrm{Zr}=1.60 \pm 0.05$ is attained by arranging the pressure in the system.

Hydriding reaction of $\mathrm{UZr}$ at a temperature of $800^{\circ} \mathrm{C}$ can be written as follow:

$$
U \mathrm{Zr}+0.8 \mathrm{H}_{2} \Leftrightarrow U+\mathrm{ZrH}_{1.6}
$$

To calculate the hydrogen concentration in the system the equation below is used:

$$
n_{a b s}\left(P_{S C}^{e q}\right)=\frac{\Delta P_{R C} V_{R C}}{R T_{R C}}-\frac{\Delta P_{S C} V_{S C}}{R T_{S C}}
$$

where $n_{a b s}\left(P_{S C}^{e q}\right)$ is the number of hydrogen absorbed in the specimen under equilibrium state, $\Delta P_{R C}$ is reservoir pressure, $V_{R C}$ is reservoir volume, $\Delta P_{S C}$ pressure in the specimen holder, $V_{S C}$ is volume of specimen holder, $R$ is gas ideal constant, $T_{R C}$ is reservoir temperature and $T_{S C}$ is holder temperature. Equation (3) is not ideal and need to be revised due to the uncertainty of the equipment and therefore a little corection is required. The maximum $\mathrm{H} / \mathrm{Zr}$ atomic ratio should be $<1.7$ [18].

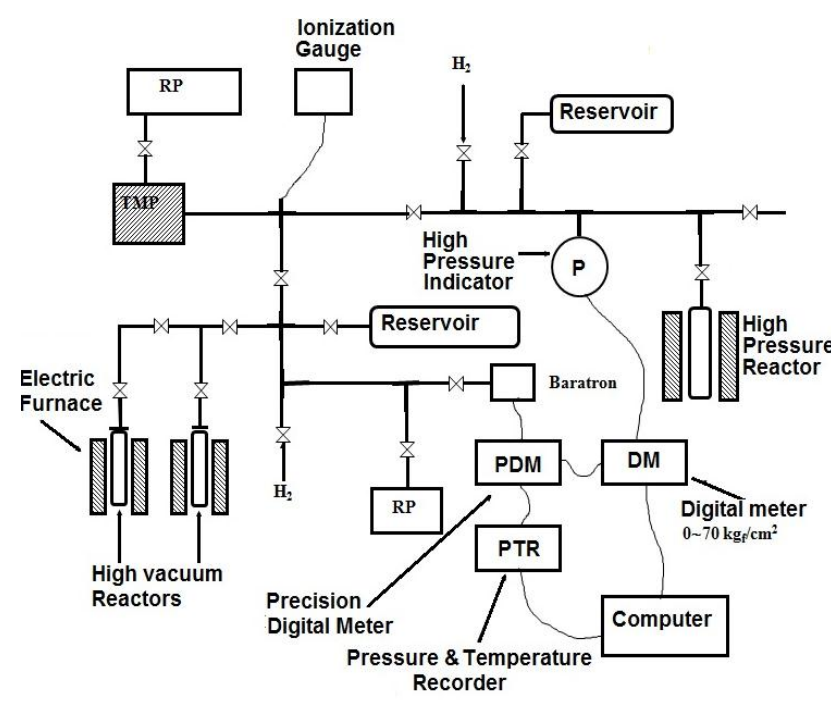

Fig. 8. Hydriding system developed by the Author. 
Figure 9 shows the $\mathrm{UZrH}_{1.6}$ pellet made by the Author, where no specific change and only a view change from metallic color before hydriding into bleary one after hydriding [19-21]. The volumetric expansion due to hydriding is $\pm 5 \%$ [22]. The expansion still fulfills the specification required.

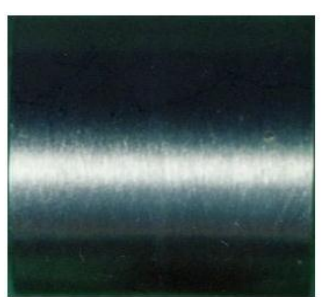

(a)

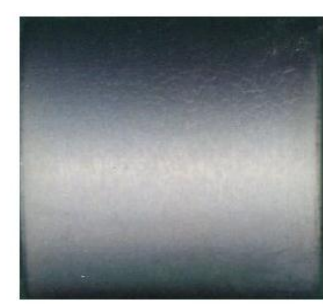

(b)
Fig. 9. UZr pellet (a) before and (b) after hydriding made by this system.

\section{Cladding and other components preparations}

Figure 10 shows the components of a TRIGA fuel element to be fabricated. It consists of 10 or $15 \mathrm{UZrH}_{1.6}$ pellets, a zirconia rod, a cladding, two pieces of graphite, top and bottom caps. The diameters of cladding, graphite, and zirconia rod materials are procured at a final dimension and therefore only view works are required, i.e. cutting them into final length. Only few and common tools are required for finishing the component preparations and already provided by the laboratory.

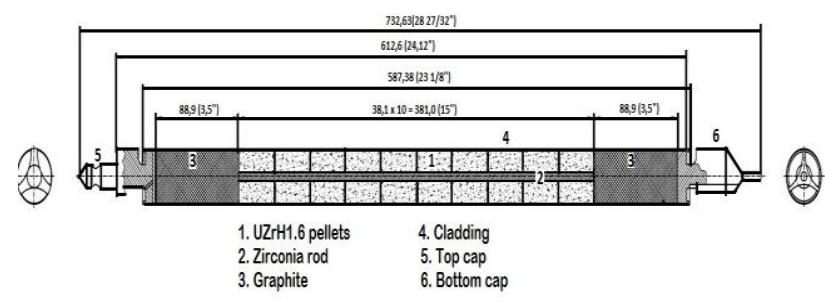

Fig. 10. TRIGA-2000 Bandung's fuel components.

\section{Fabrication of TRIGA fuel rod}

A simple procedure is used to fabricate all the components into a fuel rod. All the 10 or 15 pellets are assembled with a $\mathrm{Zr}$ rod. The bottom cap and cladding are welded, the graphite for bottom part is inserted into the cladding, rod with pellets is inserted into the cladding, followed by inserting the top part of graphite and finally the top cap. After the components are assembled as one unit, it is put into the welding machine for automatic welding of the top cap part with the cladding. An automatic welding machine is being designed by the Author.

\section{Discussion}

According to the GA the number of fuel element depends on the power of the TRIGA reactor types, as presented in Table 1 [4]. There are three TRIGA fuel cladding types in the world, namely $\mathrm{Al}$ 6061, SS 304L, and Incoloy 800. When the Al 6061 and SS 304L are used the dimensions of cladding are 1.5 in diameter and 30 in long, with the total weight around 2.9 and $30 \mathrm{~kg}$. In case of Incoloy 800 , the dia is 1.5 in and the length is 45-66.5 in. For TRIGA 2000, Mark II type, Bandung that using natural convection cooling, the number of fuel is 100 rods. At first, it employed Al 6061 type before and switching into SS 304L in order to increase the burnup from $10-20 \%$ into $30-45 \%$. In addition, this type of fuel rod can be used also be used also in the boiling water reactors (BWR) types $[23,24]$.

Table 1. TRIGA reactor power and number of fuel rods [4].

\begin{tabular}{cc}
\hline Power $(\mathrm{kW})$ & Number of fuel \\
\hline$<100$ & 60 \\
$<600$ & 65 \\
$<1500$ & 80 \\
1500 & 90 \\
2000 & 100 \\
\hline
\end{tabular}

In case of hydrogen concentration in the alloy, Olander proposed different method to control the hydrogen content [25]. Suppose the alloy composed of $\left(\mathrm{U}_{y} \mathrm{Zr}\right) \mathrm{H}_{x}$, where $x$ is the $\mathrm{H} / \mathrm{Zr}$ ratio and $y$ was the $\mathrm{U} / \mathrm{Zr}$ ratio, therefore:

$$
\begin{gathered}
y=\frac{N_{U}}{N_{Z r}} \\
\text { where, } N_{Z r}=\frac{(6.02)\left(10^{23}\right) \rho\left(1-w_{U}\right)}{91.2}
\end{gathered}
$$

$\rho$ the density of fuel and $w_{\mathrm{u}}$ the weight fraction of $\mathrm{U}$. Weight fraction and atomic ratio can be formulated by:

$$
y=\frac{91.2}{M_{U}} \frac{w_{U}}{1-w_{U}}
$$

where $M_{U}$, the atomic weight of $\mathrm{U}\left({ }^{235} \mathrm{U}+{ }^{238} \mathrm{U}\right)$.

The $\mathrm{U}$ density at room temperature, $\rho_{U}=19.9 \mathrm{~g} / \mathrm{cc}$ and the density of $\mathrm{ZrH}_{x}$ can be formulated by:

$$
\begin{aligned}
& \rho_{Z r H_{x}}=(0.154+0.0145 x)^{-1} g / c c \quad x<1.6 \\
& \rho_{Z r H_{x}}=(0.171+0.0042 x)^{-1} g / c c \quad x>1.6
\end{aligned}
$$


Therefore, the density of the two-phase mixture was:

$$
\rho=\left(\frac{w_{U}}{\rho_{U}^{o}}+\frac{1-w_{U}}{\rho_{Z r H_{x}}}\right)^{-1}
$$

The density of fuel can be formulated by:

$\rho_{U}=w_{U} \rho$

The maximum of $w_{U}=0.45$ (Chesworth and West, 1985), and the molecular weight of hydrid compound can be formulated as follows:

$$
M=y M_{U}+91.2+x
$$

The above formulae is another method proposed by Olander.

Checcheto [26] did not use the above formulae to control the hydrogen content, but similar to the Author's method (Eq. 3). It is easily understood because of the simply of the equation used.

The TRIGA 2000 fuel consists of simple components. Only $\mathrm{UZrH}_{1.6}$ pellet seems specific. The other components, i.e. a SS 304 cladding, a $\mathrm{Zr}$ rod, two pieces of graphite, and top and bottom caps do not need specific preparation. These materials are procured in the form of final dimension of TRIGA 2000 fuel, except for the lengths of cladding, rod, and graphite. Therefore, only cutting of the SS $304 \mathrm{~L}, \mathrm{Zr}$ rod, and graphite into final dimensions is required. In case of the top and bottom caps, it can be done easily in a precision frais machine provided in the laboratory. To fabricate all the components into TRIGA 2000 fuel rod only an automatic welding machine and working bench are required.

Figure 11 shows the UZrH1.6 prototype fuel that has been prepared by the Author, presented together with the UThZrH alloys. These prototype fuels had been irradiated successfully in the JRR 30, Oarai, Japan during his research under Post Doctoral Degree program at the University of Tokyo, Japan, under supported by the Japan Atomic Energy Agency (JAEA)[27].

Fresh fuel required for operation of the reactor needs about 78 rods [28]. Referring to the fabrication of TRIGA-2000 fuel, the critical path for mass production depends on the hydriding systems, i.e. number of hydrided pellet production. Referring to Fig. 8, the hydriding systems can be expanded its $\mathrm{UZrH}_{1.6}$ pellet production from 1-2 pellets into 30 pellets per day by modifying the system. Therefore, mass production of the TRIGA-2000 fuel rods can be materialized.

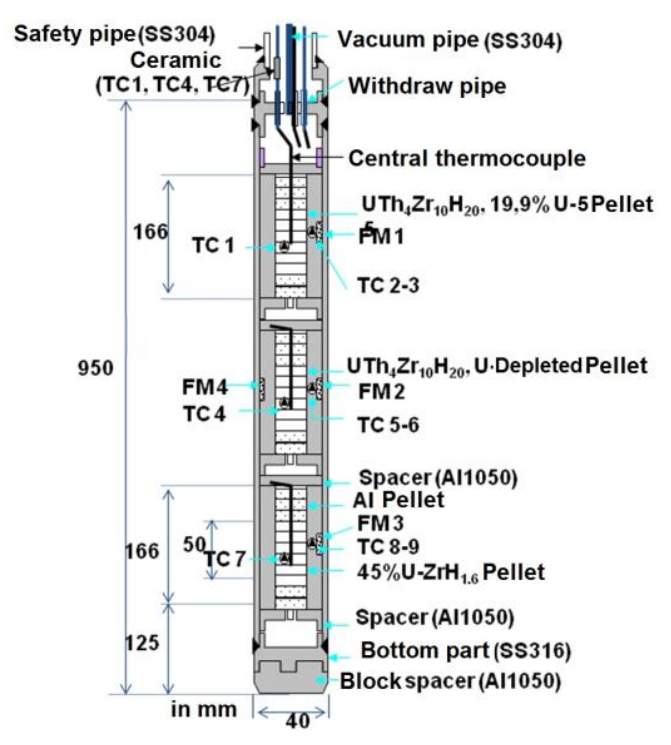

(a)

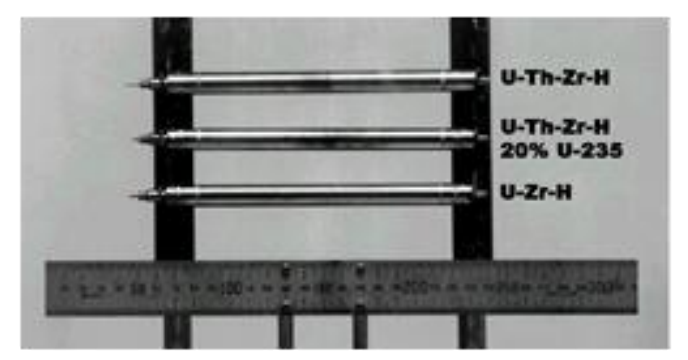

(b)

Fig. 11. (a) A capsule containing fuel bundles of $\mathrm{UZrH}_{1.6}$ and $\mathrm{UTh}_{4} \mathrm{Zr}_{10} \mathrm{H}_{20}$ and (b) after dismantling in a Hot-Lab [27].

\section{CONCLUSION}

TRIGA-2000 fuel element can be developed at the PTBBN-BATAN by modifying the GA fabrication method (melting) into powder technique.

Sievert system developed by the Author can be used to prepare the $\mathrm{U}$ powders and $\mathrm{UZrH}_{1.6}$ pellet precisely according to the TRIGA specification required.

The facility in the PTBBN laboratory can be used to fabricate the TRIGA-2000 Bandung fuel rods with only minor equipment requirement.

Experience of the Author in converting uranium metal into powders and preparing $\mathrm{UZrH}_{\mathrm{x}}$ pellets becomes the most valuable provision.

The success in TRIGA-2000 fuel fabrication will result in the continued operation of the reactor.

\section{ACKNOWLEDGMENT}

The Author would like to acknowledge Mr. Abdul Rodjak for providing the drawing of TRIGA-2000 fuel element. 


\section{REFERENCES}

1. M.T. Simnad, F. Foushe and G. West, Nucl. Technol. 28 (1976) 3.

2. M.T. Simnad, Nucl. Eng. Des. 64 (1981) 403.

3. G. Hampel, The Importance of TRIGA Reactors, on Behalf of the European TRIGA community, Johannes Gutenberg-Universitat Mainz D-55099, $9^{\text {th }}$ April (2010).

4. C.D. West, Neutron News 10 (1999) 28.

5. N. Tomsio, Characterization of TRIGA Fuel, ORNL/Sub/86-22047/3, GA-C18542, GA Project 3442 Report, California, October (1986).

6. W.P. Wallace, M.T. Simnad and B. Turovlin, Nucl. Metall. 5 (1958) 49.

7. I.F. Weeks, Livermore and W.V. Doeddel, Method of Fabricating A Uranium-Zirconium Hydride Reactor Core, US Patent Office 2, 929, 707 (1960).

8. M. Simnad, Method of Fabricating a Fuel Element, US Patent 3, 135, 697 (1964).

9. G.H. Eggers, Method of Making ZrH Fuel Element, US Patent 4, 071, 587 (1978).

10. H. Suwarno, K. Asada and M. Yamawaki, Hydriding-Dehydriding of Uranium, Proceeding The $3^{\text {Rd }}$ Scientific Meeting, Indonesian Atomic Energy Student in Japan, Tokyo Institute of Technology, Tokyo, March 4 (1994) 257.

11. H. Suwarno, Adv. Mat. Res. 789 (2013) 360.

12. T.B. Massalski, Binary Alloys Phase Diagrams, in: Metal Park, OH: The American Society for Metals, $2^{\text {nd }} E d .3$ (1990) 2070.

13. P.M. Portillo, Quality by Design for Continuous Powder Mixing, Ph.D. Thesis, The State University of New Jersey (2008).

14. Anonymous, Part II, Proces Description, in: BATAN License Contract Betwen
Republic of Indonesia and NUKEM GmbH (1982).

15. Anonymous, Part III, Specification of U-Al and $\mathrm{U}_{3} \mathrm{O}_{8}$ Fuel, in: BATAN License Contract Betwen Republic of Indonesia and NUKEM $\mathrm{GmbH}$ (1982).

16. H. Suwarno, Indonesian J. Mater. Sci., Special Ed, Dec. (2008) 153. (in Indonesian)

17. H. Suwarno and W.A. Adi, Atom Indonesia 35 (2009) 127.

18. M.T. Simnad, Uranium Thorium Hydride Nuclear Fuel, US Patent 4, 493, 809 (1985).

19. H. Suwarno, T. Yamamoto and F. Ono, et al., J. Nucl. Mater. 247 (1997) 333.

20. T. Yamamoto, H. Suwarno, H. Kayano, et al., J. Nucl. Mater. 247 (1997) 339.

21. H. Suwarno, Feasibility Study of U-Th-Zr Hydrides as Nuclear Fuel Materials, Ph.D Thesis, University of Tokyo (1998).

22. M. Yamawaki, H. Suwarno, T. Yamamoto, et al., J. Alloys Compd. 271-273 (1998) 530.

23. E. Greenspan, BWR Fuel Assembly Having Oxide and Hydride Fuel, US Patent 5349618 (1994).

24. G. West, High Power Test of Low Enriched UZrH, http://library.sinap.ac.cn/db/ yuanjian201003/\%E5\%85\%A8\%E6\%96\%87/4 0029000.pdf. Retrieved in April (2013).

25. D. Olander, E. Greenspan, H.D. Garkisch, et al., Nucl. Eng. Des. 23 (2009) 1406.

26. R. Checchetto, G. Trettel and A. Miotello, Meas. Sci. Technol. 15 (2004) 127.

27. H. Suwarno, Study PIE Technique in the Department of Hot Laboratory, in: Technical Report under Post Doctorate Program, Tokaimura, Ibaraki, Japan Atomic Energy Research Institute (1999).

28. P.I. Yazid, Status of TRIGA 2000-Bandung, Oral Report, Bandung (2013). (in Indonesian) 